\title{
[ 293 ]
}

\section{III.}

BITUMINŌSES KOHLENWASSERSTOFFGAS, und ein auf eine befondere Art erzeugtes Oehl;

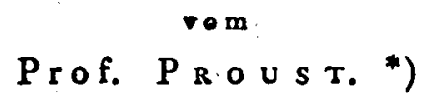

Die Verfuche Lavoifier's Jaffen keinen Zweifel iber die Beftandtheile der fetten Körper aus dem Thierreiche und aus dem Pflanzenreiche. Der Wafferftoff, vermöge feiner grofsen Verwandtfchaft zum Kohlenftoffe, vereinigt fich mit ihm in concreter Form nach,verfohiodnen Verhältniffen und bildet fo im Allgemeinen die Oeble.

Wir haben nicht die mindefte Hoffnung, durch Kunft diefe Verbindung des Wafferft offs mit dem Kohlenftoffe nachahmen zu können, welche die Natur täglich unter unfern Augen in den organifirton Wefen hervor bringt. $Z$ war haben uns einige ältere Chemiker wollen glauben machen, fie hätten Oehl erzeugt, in dem Prozeffe, deffen man fich jefzt zur Entbindung der oxygenirten Salzfäure bedient; bei genauerer Prüfung verfchịand aber die Täufchung, und man fand, dals es Oehl aus ihren fetten Kitten war.

*) Journal de Phyfique, 1799, Aug., p. 155. \&. H. 


\section{[ 294 ]}

Die Erzeugung von Oelıl, auf die ich hier aufmerkfam machen will, ift nicht etwas Zufälliges, oder etwas, das' auf befondern Magipulationen berubt, und dem einen glückt, dem andern mifs. liugt. Sie findet jedes Mahl Statt, wenn Gu/seifen in Schucefelfüure oder in Salzfüure aufgelöf zeird. Jeiles MIahl entwickelt fich hierbei ein öhliges li aflerjongas, welches fchwer und fehr riechend ift. Ler Guruch deffeiben ift beftimmt bituminös oder bermfetinartig, und gänzlich verfchieden von clem, cler fich beim Auflöfen von Schmiedeeifen verbreitet.

Priefiley hat diefen Unterfchied fehr rich. tig waligetommen, und fpricht von dem erften Wafferfroffyas als von einer aufserordentlich foinkenden brennbaren Lujt. Er bemerkt, dals der unauflüsliche Rückftand von gegofsnen Nägeln, die er aufgelöft hatte, denfelben Geftank als die Luft hatte, die dabei überging; eben fo das fchwarze Pulver, welches bei einer vollftändigern Auflüfung fich davou atfohied. Auch an andern Stellen bemerkt er, dals die brennbare Luft aus Gufseifen einen befondern Geftank hat.

Ich habe häufig das Gufseifen unterfucht, woraus mail in Spanien die eifernen Kanonen, die Eumben, die Kugeln u. f. f. verfertigt, und ftets bemerist, dafs die Kolben und Retorten, in denen min cie Aullöfung vornimmt, fettig find; Waffer reicht nicht aus, fie zu reinigen, fondern man mufs 


\section{[ 295$]$}

dazu Weingeift nehmen. Diefer nimmt dann denfelben Geruch an, und wird mit Waffer milchig, wie wenn èr ein wefentliches Oehl aufgelöft enthielte.

Das Reifsblei, welches bei dem Auflöfen von Gufseifen in den erwähnten Säuren zurück bleibt, enthält, auch nachdem es gewafchen und getrocknet worden, gleichfalls etwas von diefem Oeble; man befreiet es davon, wenn man es in einer Retorte bei mäfsiger. Wärme erhitzt. Wird es in einem offnen Gefäfse erhitzt, fo entzündet es fich zuweilen, und brennt fo lange, bis alles dieles Oehl zerftört ift. Auch der Weingeift entzieht dem zurück bleibenden Reifsblei diefes Oehl.

Ich habe verfucht, 18 Unzen Gufseifen in Säuren, die mit Weingeift vermilcht worden waren, aufzulöfen, um zu fehen, ob ich nicht beim Deftilliren diefes $\mathrm{Oehl}$ in einiger Menge erhalten würde. Ich habe davon aber nie mehr als einige Tropfen bekommen, und zwar, wie es mir fchien, weil immer das Walferltoffgas das meifte mit fortnahm. Diefelbe Bewandtnils hat es mit dem Wafferftoffgas, welches tich bei der zerftörenden Deftillation der Oelule entwickelt; es ift fo mit Oehl beladen, und dadurch fo fchwer, dafs es fich aus einem Gefäfse in das andre gielsen lälst, wie das kohlenfaure Gas.

Doch diefem fey, wie ihm wolle, fo- viel ift gewifs, dafs jene Oehlerzeugung bei jeder Auflöfung von Gufseifen in Säuren Statt findet, und dafs der rom Eilea fich abfcheidende Kohlenftoff hierbei, 


\section{[ 296 ]}

durch leine Vereinigung mit dein Walferftoffe, in den Zuftand der vegetabilif́chen Koble zurück tritt. *)

*) Hier noch eine Stelle aus einem Briefe von Proult an Vauquelin, gefchrieben. Madrit den 6ten Nov. 1803. (Ann. de Chimie, t.49, p. 187.) "Mein Gehülfe befchäftigt fich mit der Reinigung des Manganesinetalles; er erhält es in Körn. chen, aber nicht in einer zufammen gefclinolznen Mlaffe: Fourcroy hat Recht, diele Körm. chen riechen, wenn fie zerfallen, nach Wafferftoffgas. Das Wafferftoffgas, welches auffteigt, wenn fie in Schwefelfäure aufgelöft werden, ift dem aus fchwarzem Gufreilen to ähnlich, dafs ich vermuthe, auch das Manganes könne Kohle auflö[en."

d. H. 